\title{
Expression of TRAIL and the death receptors DR4 and DR5 correlates with progression of degeneration in human intervertebral disks
}

\author{
Helge Bertram ${ }^{1}$, Andreas Nerlich ${ }^{2}$, Georg Omlor ${ }^{1}$, Florian Geiger ${ }^{1}$, Gerald Zimmermann ${ }^{3}$ \\ and Joerg Fellenberg ${ }^{1}$ \\ ${ }^{1}$ Division of Experimental Orthopaedics, Orthopaedic University Clinic Heidelberg, Heidelberg, Germany; \\ ${ }^{2}$ Institute of Pathology, Academic Hospital Bogenhausen, Munich, Germany and ${ }^{3}$ BG Trauma Center \\ Ludwigshafen, University of Heidelberg, Ludwigshafen, Germany
}

\begin{abstract}
Intervertebral disks degenerate far earlier than other musculoskeletal tissues and apoptosis has been suggested to have a vital function in promoting the degeneration process that is strongly associated with back pain. However, the molecular mediators of apoptosis in the intervertebral disk are poorly understood. Fas/FasL, TRAIL/DR4, TRAIL/DR5 and TNF- $\alpha$ /TNFR1 are ligand/receptor pairs of the tumor necrosis factor/nerve growth factor family, which are able to induce apoptosis by trimerization of the receptor by its corresponding ligand. We investigated which of these molecules are expressed in intervertebral disks and whether their expression correlates to disk degeneration. Intervertebral disks from 28 donors (age 12-70 years) suffering from scoliosis, vertebrae fracture or disk degeneration were scored histologically for degeneration and analyzed for gene expression of FasL/Fas, TRAIL/DR4, TNF- $\alpha$ TNFR1 and caspase 8. Protein expression of FasL and TRAIL was assessed by immunohistology and apoptotic cell death was quantified by poly(ADP-ribose) polymerase (PARP) p85 staining. Isolated disk cells were analyzed by flow cytometry for Fas, FasL, TRAIL, DR4 and DR5 expression. Gene expression of TRAIL $(P=0.002)$ and caspase $8(P=0.027)$ significantly correlated with degeneration. TRAIL expression further correlated with cellularity $(P=0.04)$, muccoid matrix changes $(P=0.009)$ and tears and cleft formation $(P=0.019)$. FasL and TRAIL expression was confirmed by immunohistology and PARP cleavage was significantly associated with degeneration $(P=0.027)$. Flow cytometry on isolated disk cells revealed correlations between DR4 and degeneration $(P=0.014)$, DR4/DR5 double-positive cells and degeneration $(P=0.019)$, as well as DR5 and changes in tissue granularity $(P=0.03)$. This is the first study that shows that intervertebral disk cells express TRAIL, DR4 and DR5, which correlate to the degenerative state of the disk. Therefore, disk cells inherit the molecular machinery to induce and undergo cellular apoptosis, and the frequency of cytokine expression suggests that the TRAIL/DR4/DR5 axis is an important molecular mediator of apoptosis induction in disk tissue.
\end{abstract}

Modern Pathology (2009) 22, 895-905; doi:10.1038/modpathol.2009.39; published online 20 March 2009

Keywords: apoptosis; TRAIL; DR4; DR5; intervertebral disk; degeneration

Low back pain is a leading cause of morbidity. It is estimated that about $70 \%$ of the population will experience low back pain during their lives. ${ }^{1}$ In recent years, intervertebral disk disorders and agerelated degeneration have been significant contributors to low back pain and spine-related disability.

The intervertebral disk is the largest avascular organ in the body, populated by highly differen-

Correspondence: Dr H Bertram, PhD, Division of Experimental Orthopaedics, Orthopaedic University Clinic Heidelberg, Schlierbacher Landstrasse 200a, D-69118 Heidelberg, Germany.

E-mail: helgebertram@gmx.de

Received 3 February 2009; revised 19 February 2009; accepted 20 February 2009; published online 20 March 2009 tiated cells within an extensive extracellular matrix. The nucleus pulposus is highly hydrated and proteoglycan rich encapsulated by the dense collagenous fibrous tissue of the annulus fibrosus and by the cartilaginous endplates.

There is great interest in understanding the complex pathogenesis of intervertebral diseases, and recent reports of the existence of apoptotic cells in intervertebral disks have provided a new insight into the pathophysiology of disk degeneration. ${ }^{2-8}$ It is believed that the degeneration is the consequence of mechanical and biological events that destabilize the normal equilibrium between matrix synthesis and degradation. Advances in cellular and molecular biology techniques have promoted the 
understanding of pathogenic mechanisms underlying intervertebral disk degeneration. ${ }^{9-13}$ In vivo and in vitro studies have indicated that apoptosis has a central function in the degenerative process. ${ }^{10}$ Among many factors associated with cellular apoptosis, members of the tumor necrosis factor (TNF) family are believed to have a critical function. ${ }^{2,14-18}$ Apoptosis is a naturally occurring physiological process that is involved in various processes that require controlled tissue turnover during mammalian development including embryogenesis, tissue atrophy and homeostasis of the immune system.

One of the best-studied apoptosis pathways is the FasL/Fas system. ${ }^{19-21}$ The apoptosis-inducing ligand and TNF/nerve growth factor (NGF) family member FasL is expressed predominantly in activated $\mathrm{T}$ lymphocytes and stromal cells of immune-privileged sites, such as the eye, testis, and brain, ${ }^{20-26}$ whereas its membrane-bound receptor Fas is expressed in various cells of certain organs such as the thymus, liver, kidney, and heart. ${ }^{2,27-30}$

Trimerization of the membrane-bound receptor Fas by its natural ligand FasL leads to the recruitment of several well-characterized molecules to the intracellular 'death domain' of the receptor, forming the so-called death-inducing signaling complex. $^{23,31,32}$ Subsequent autocatalytic activation of downstream caspases involving caspase 8 results in the caspase 3-mediated cleavage of specific substrates, including poly(ADP-ribose) polymerase (PARP) and thus triggers the apoptotic process. ${ }^{33,34}$ Increased cellular apoptosis rate in lumbar disk tissue has been detected in the past mainly by TUNEL (terminal deoxynucleotidyl transferase dUTP nick end labeling) assay. ${ }^{7}$ In addition, expression of Fas and FasL has been described for noncontained herniated disks. ${ }^{6,35}$ Three common apoptosis-inducing factors, FasL, TNF- $\alpha$, and TNFrelated apoptosis-inducing ligand (TRAIL), are known to trigger apoptosis through distinct signaling pathways. ${ }^{6,7,32,35-38}$ Currently, it remains unclear whether other members of the TNF superfamily such as the death receptors DR4 and DR5 are involved in degenerative disk disease and may contribute to the pathology of the disk degeneration.

Therefore, the current study aims to examine the questions: which ligand/receptor pairs of the TNF/NGF family are expressed on native intervertebral disk tissue and cultured intervertebral disk cells that might contribute to apoptotic cell death during disk degeneration. Second, if present, does the expression of these molecules correlate to pathological parameters of the degenerative grade of the disk tissue? The results of this study would lay an important foundation for the hypothesis that TRAIL and its receptors DR4 and DR5 may represent a potential pathway for apoptosis induction in the intervertebral disk contributing to ongoing degeneration observed in degenerative disk disease.

\section{Materials and methods}

\section{Intervertebral Disk Tissue}

Tissue was obtained during surgery, according to approval by the local ethics committee. Tissue underwent molecular and morphological investigation and was also subjected to histological grading (Table 1) based on an established method that characterizes the degenerative grade of the disk tissue. The method takes into account five parameters of pathological tissue transformation and results in a score ranging from 0 for undegenerated disk tissue up to 22 for heavily degenerated tissue. ${ }^{16}$

The study group comprised 28 individuals with idiopathic scoliosis, acute trauma of vertebrae or degenerative disk disease requiring surgical intervention. Age range was $12-70$ years (mean 32.7 years) and the mean grade of histological degeneration was 5.1 .

\section{Intervertebral Disk Cell Isolation and Cultivation}

For intervertebral disk cell isolation, we digested tissue overnight at $37^{\circ} \mathrm{C}$ with permanent rotation in $10 \mathrm{ml}$ Dulbecco's modified Eagle's medium (Invitrogen, Karlsruhe, Germany) containing $333 \mu \mathrm{g} / \mathrm{ml}$ collagenase B (Roche Diagnostics, Mannheim, Germany) and $200 \mu \mathrm{g} / \mathrm{ml}$ hyaluronidase (Serva, Heidelberg, Germany). Isolated intervertebral disk cells were separated from digest solution by a centrifugation step at $400 \mathrm{~g}$ for $10 \mathrm{~min}$, washed in phosphatebuffered saline (PBS) and cultured in monolayer in Dulbecco's modified Eagle's medium supplemented with 10\% fetal calf serum (Biochrom, Berlin, Germany), and 1\% penicillin/streptomycin (Biochrom) at $37^{\circ} \mathrm{C}$ and $5 \% \mathrm{CO}_{2}$.

\section{Flow Cytometry}

For the detection of membrane-bound and intracellular apoptosis-related receptors and ligands, cultured intervertebral disk cells were washed in PBS, trypsinized with trypsin/EDTA (Lonza, Wuppertal, Germany) and counted. After fixation in PBS containing $2 \%$ paraformaldehyde (Sigma, Taufkirchen, Germany) at $37^{\circ} \mathrm{C}$ for $15 \mathrm{~min}$, we permeabilized $5 \times 10^{5}$ cells in $500 \mu \mathrm{l}$ PBS containing $0.5 \%$ Triton X-100 (Sigma) and $4 \%$ fetal calf serum at $4^{\circ} \mathrm{C}$ for $5 \mathrm{~min}$. The permeabilized cells were stained for $30 \mathrm{~min}$ at room temperature with the following fluorescein (FITC)- or phycoerythrin (PE)conjugated antibodies according to the manufacturer's instructions: FAS-L (NOK-1)-FITC (Santa Cruz, Heidelberg, Germany), FAS-L (NOK-1)-PE (Santa Cruz), FAS-FITC (Santa Cruz), TRAIL-PE (BD Biosciences, Heidelberg, Germany), TRAIL-R1 (DR4)-PE (R\&D Systems, Wiesbaden-Nordenstadt, Germany), TRAIL-R2 (DR5)-FITC (Alexis Biochemicals, Lörrach, Germany). After antibody incubation, 
Table 1 Patient characteristics and morphological observations

\begin{tabular}{|c|c|c|c|c|c|c|c|c|c|c|c|c|c|}
\hline \multirow[b]{2}{*}{$I D$} & \multirow[b]{2}{*}{ Age } & \multirow[b]{2}{*}{ Sex } & \multirow[b]{2}{*}{ Diagnosis } & \multirow[b]{2}{*}{ Level } & \multicolumn{5}{|c|}{ Morphological characteristics } & \multirow{2}{*}{$\begin{array}{l}\text { HDS } \\
\text { score }\end{array}$} & \multirow[t]{2}{*}{ PARP } & \multirow{2}{*}{$\begin{array}{l}\text { Flow } \\
\text { cytometry }\end{array}$} & \multirow[t]{2}{*}{$q P C R$} \\
\hline & & & & & $\begin{array}{l}\text { Cellularity } \\
\qquad(0-5)^{\mathrm{a}}\end{array}$ & $\begin{array}{l}\text { Granularity } \\
\qquad(0-3)^{\mathrm{a}}\end{array}$ & $\begin{array}{c}\text { Tears+clefts } \\
(0-3)^{\mathrm{a}}\end{array}$ & $\begin{array}{c}\text { Muccoid } \\
(0-3)^{\mathrm{a}}\end{array}$ & $\begin{array}{c}\text { Necrosis } \\
(0-3)^{\mathrm{a}}\end{array}$ & & & & \\
\hline 1 & 12 & $\mathrm{~m}$ & Scoliosis & $\mathrm{L} 3 / 4$ & 1 & 0 & 0 & 2 & 0 & 3 & $\mathrm{X}$ & $\mathrm{X}$ & $\mathrm{X}$ \\
\hline 2 & 12 & $\mathrm{f}$ & Scoliosis & $\mathrm{L} 1 / 2$ & 1 & 1 & 1 & 2 & 0 & 5 & NA & NA & $\mathrm{X}$ \\
\hline 3 & 14 & $\mathrm{~m}$ & Scoliosis & $\mathrm{L} 3 / 4$ & 2 & 0 & 1 & 0 & 0 & 4 & $\mathrm{X}$ & $\mathrm{X}$ & $\mathrm{X}$ \\
\hline 4 & 14 & $\mathrm{~m}$ & Scoliosis & $\mathrm{L} 4 / 5$ & 3 & 0 & 2 & 2 & 0 & 7 & NA & $\mathrm{X}$ & $\mathrm{X}$ \\
\hline 5 & 14 & $\mathrm{f}$ & Scoliosis & $\mathrm{L} 2 / 3$ & 1 & 1 & 1 & 2 & 0 & 5 & NA & NA & $\mathrm{X}$ \\
\hline 6 & 15 & $\mathrm{f}$ & Scoliosis & T12/L1 & 3 & 1 & 1 & 2 & 0 & 7 & $\mathrm{X}$ & $\mathrm{X}$ & $\mathrm{X}$ \\
\hline 7 & 15 & $\mathrm{~m}$ & Scoliosis & $\mathrm{L} 4 / 5$ & 3 & 3 & 2 & 2 & 0 & 10 & $\mathrm{X}$ & $\mathrm{X}$ & NA \\
\hline 8 & 16 & $\mathrm{f}$ & Scoliosis & $\mathrm{L} 2 / 3$ & 1 & 0 & 1 & 1 & 0 & 3 & $\mathrm{X}$ & NA & $\mathrm{X}$ \\
\hline 9 & 16 & $\mathrm{f}$ & Scoliosis & $\mathrm{T} 11 / 12$ & 1 & 0 & 1 & 1 & 0 & 2 & $\mathrm{X}$ & NA & $\mathrm{X}$ \\
\hline 10 & 16 & $\mathrm{~m}$ & Scoliosis & $\mathrm{L} 2 / 3$ & 4 & 0 & 1 & 2 & 0 & 7 & $\mathrm{X}$ & $\mathrm{X}$ & NA \\
\hline 11 & 17 & $\mathrm{f}$ & Scoliosis & $\mathrm{L} 2 / 3$ & 3 & 2 & 1 & 1 & 0 & 7 & $\mathrm{X}$ & NA & $\mathrm{X}$ \\
\hline 12 & 19 & $\mathrm{f}$ & Trauma & T12/L1 & 2 & 0 & 1 & 1 & 0 & 4 & NA & NA & $\mathrm{X}$ \\
\hline 13 & 26 & $\mathrm{f}$ & Scoliosis & $\mathrm{L} 4 / 5$ & 3 & 0 & 2 & 3 & 0 & 7 & $\mathrm{X}$ & $\mathrm{X}$ & NA \\
\hline 14 & 28 & $f$ & Trauma & $\mathrm{T} 10 / 11$ & 2 & 0 & 1 & 0 & 0 & 3 & $\mathrm{X}$ & NA & $\mathrm{X}$ \\
\hline 15 & 28 & $\mathrm{~m}$ & Trauma & $\mathrm{T} 11 / 12$ & 1 & 0 & 0 & 2 & 0 & 3 & $\mathrm{X}$ & NA & $\mathrm{X}$ \\
\hline 16 & 30 & $\mathrm{f}$ & Trauma & $\mathrm{T} 11 / 12$ & 2 & 0 & 1 & 2 & 0 & 4 & NA & NA & $\mathrm{X}$ \\
\hline 17 & 31 & $\mathrm{~m}$ & Trauma & T12/L1 & 1 & 0 & 0 & 1 & 0 & 2 & $\mathrm{X}$ & NA & $\mathrm{X}$ \\
\hline 18 & 32 & $\mathrm{f}$ & Trauma & T12/L1 & 1 & 0 & 1 & 2 & 0 & 4 & NA & NA & $\mathrm{X}$ \\
\hline 19 & 45 & $\mathrm{f}$ & Trauma & T12/L1 & 2 & 0 & 0 & 1 & 0 & 3 & $\mathrm{X}$ & NA & $\mathrm{X}$ \\
\hline 20 & 49 & $\mathrm{~m}$ & Degenerate & $\mathrm{L} 3 / 4$ & 0 & 0 & 1 & 2 & 0 & 3 & $\mathrm{X}$ & $\mathrm{X}$ & $\mathrm{X}$ \\
\hline 21 & 50 & $\mathrm{f}$ & Degenerate & $\mathrm{L} 4 / 5$ & 3 & 1 & 1 & 2 & 0 & 7 & NA & NA & $\mathrm{X}$ \\
\hline 22 & 50 & $\mathrm{~m}$ & Degenerate & $\mathrm{L} 2 / 3$ & 2 & 0 & 2 & 1 & 0 & 5 & $\mathrm{X}$ & $\mathrm{X}$ & $\mathrm{X}$ \\
\hline 23 & 54 & $\mathrm{~m}$ & Degenerate & $\mathrm{L} 2 / 3$ & 3 & 1 & 1 & 3 & 0 & 8 & $\mathrm{X}$ & $\mathrm{X}$ & $\mathrm{X}$ \\
\hline 24 & 55 & $\mathrm{~m}$ & Trauma & T12/L1 & 0 & 0 & 1 & 1 & 0 & 2 & $\mathrm{X}$ & NA & $\mathrm{X}$ \\
\hline 25 & 55 & $\mathrm{~m}$ & Trauma & $\mathrm{T} 11 / 12$ & 3 & 1 & 2 & 1 & 0 & 7 & $\mathrm{X}$ & $\mathrm{X}$ & NA \\
\hline 26 & 64 & $\mathrm{~m}$ & Degenerate & $\mathrm{L} 1 / 2$ & 2 & 2 & 2 & 3 & 0 & 9 & $\mathrm{X}$ & $\mathrm{X}$ & $\mathrm{X}$ \\
\hline 27 & 69 & $\mathrm{f}$ & Degenerate & $\mathrm{L} 2 / 3$ & 2 & 1 & 1 & 2 & 0 & 6 & NA & $\mathrm{X}$ & $\mathrm{X}$ \\
\hline 28 & 70 & $\mathrm{~m}$ & Degenerate & $\mathrm{L} 4 / 5$ & 2 & 0 & 2 & 3 & 0 & 7 & $\mathrm{X}$ & $\mathrm{X}$ & $\mathrm{X}$ \\
\hline Mean & 32.7 & & & & 1.8 & 0.5 & 1.1 & 1.6 & 0.0 & 5.1 & & & \\
\hline
\end{tabular}

m, male; f, female; HDS, histological degeneration score; NA, data not available; X, analyzed.

${ }^{\mathrm{a}}$ Range.

we washed cells three times in PBS/4\% fetal calf serum and resuspended in $500 \mu \mathrm{l} \mathrm{PBS} / 4 \%$ fetal calf serum. Cells were analyzed on a FACSCalibur (BD Biosciences) and the amount of positive cells compared to FITC- or PE-labeled Mouse IgG1 isotype controls (BD Biosciences) was calculated using CellQuest Pro software (BD Biosciences).

\section{Immunohistochemistry}

For histological and immunohistochemical stainings, intervertebral disk tissue was fixed in PBS containing $4 \%$ paraformaldehyde (Sigma) for $2 \mathrm{~h}$ at $20^{\circ} \mathrm{C}$ dehydrated in alcohol, washed in acetone and infiltrated with paraffin. Paraffin sections $(3-4 \mu \mathrm{m})$ were dried, deparaffinized using the xylol replacement medium XEM-200 (Vogel, Giessen, Germany) and rehydrated in ethanol.

The cleavage of the caspase substrate PARP was analyzed using an anti-PARP p85 antibody (Promega, Mannheim, Germany) specific for an $85-\mathrm{kDa}$ cleavage fragment exclusively produced by caspases in apoptotic cells. Briefly, paraffin sections were dewaxed in XEM-200, rehydrated and pretreated with Triton X-100 (Sigma; $0.2 \%$ in PBS) for $5 \mathrm{~min}$ at ambient temperature. For detection, the ImmunoCruz $^{\mathrm{TM}}$ Staining System for use with rabbit primary antibodies (Santa Cruz) was used according to the manufacturer's protocol. The primary antibody was diluted 1:100 and diaminobenzidine was used as chromogenic substrate.

For the detection of FasL and TRAIL, we treated sections with $200 \mu \mathrm{g} / \mathrm{ml}$ trypsin/EDTA (Lonza) at $37^{\circ} \mathrm{C}$ for $15 \mathrm{~min}$, washed three times in PBS for $5 \mathrm{~min}$ and stained with rabbit anti-FasL (Santa Cruz) and goat anti-TRAIL (Santa Cruz) antibodies diluted 1:100. For detection, the VECTASTAIN ABC-AP kit for use with rabbit or goat primary antibodies (Linaris, Wertheim-Bettingen, Germany) was used according to the manufacturer's protocol. Fast Red (Roche Diagnostics) was used as chromogenic substrate. All sections were permanently mounted with Aquatex (Merck, Darmstadt, Germany) and examined by light microscopy.

\section{Tissue Processing and mRNA Isolation}

The anterior or anterolateral quadrant of each disk was removed in fragments by an anterior approach. The entire tissue (nucleus and annulus together) 
was subjected to the molecular analysis, because only insufficient gene expression signals were obtained from the nucleus alone. After resection, we rinsed the tissue with PBS and split fragments for histological and molecular processing, snapfrozen in nitrogen and stored at $-80^{\circ} \mathrm{C}$.

Frozen samples $(\sim 1 \mathrm{~g})$ were pulverized in a freezer mill (Braun, Melsungen, Germany), and 20100 ng messenger RNA (mRNA)/g intervertebral disk tissue was directly isolated after extraction in lysis/ binding buffer (100 mM Tris-HCl (pH 7.5), $500 \mathrm{mM}$ LiCl, $10 \mathrm{mM}$ EDTA, $1 \%$ LiDS, $5 \mathrm{mM}$ DTT) using oligo-(dT)-coupled magnetic beads (Dynabeads; Dynal Biotech, Norway).

For RNA isolation from cultured cells, a standard guanidinium thiocyanate/phenol extraction technique (peqGOLD TriFast; peqLab, Erlangen, Germany) was used. Polyadenylated mRNA was isolated from total RNA by using oligo-(dT)-coated magnetic beads (Dynal Biotech) as described above according to the instructions of the manufacturer.

\section{Quantitative Polymerase Chain Reaction}

First strand complementary DNA (cDNA) was synthesized from $20 \mathrm{ng}$ mRNA using $4 \mathrm{U}$ Superscript $^{\mathbb{R}}$ reverse transcriptase (Invitrogen), $1 \mu \mathrm{M}$ oligo-(dT) primer (Qiagen GmbH, Hilden, Germany), $0.5 \mathrm{mM}$ dNTPs and 0.5 U RNase Inhibitor (RNaseOUT; Invitrogen) in a total volume of $20 \mu \mathrm{l}$. Reverse transcription was carried out at $37^{\circ} \mathrm{C}$ for $2 \mathrm{~h}$. Quantitative real-time PCR was performed in a LightCycler instrument (Roche Diagnostics) in a total volume of $20 \mu \mathrm{l}$ using the LightCycler FastStart DNA Master ${ }^{\text {Plus }}$ SYBR Green I kit (Roche Diagnostics) and $1 \mu \mathrm{l}$ of cDNA as template. Samples were heated to $95^{\circ} \mathrm{C}$ for $10 \mathrm{~min}$ followed by 40 cycles of denaturation at $95^{\circ} \mathrm{C}$ for $2 \mathrm{~s}$, annealing at $58^{\circ} \mathrm{C}$ for $7 \mathrm{~s}$ and extension at $72^{\circ} \mathrm{C}$ for $14 \mathrm{~s}$. After the last cycle, a melting curve analysis was performed to verify the specificity of the amplified PCR products. The amount of PCR product was calculated using an external standard curve and the LightCycler software. Calculated gene expressions were normalized on the basis of the $\beta$-actin (ACTB) expression in the corresponding samples. The following forward and reverse primers were used for amplification:

$A C T B-F 5^{\prime}$-ctcttccagccttccttcct-3'; ACTB-R $5^{\prime}$-cgatc cacacggagtacttg-3'; FAS-F $5^{\prime}$-ataagccctgtcctccaggt-3'; $F A S-R \quad 5^{\prime}$-tcctttctcttcacccaaaca-3'; FASL-F $5^{\prime}$-ggcct gtgtctccttgtgat- $3^{\prime} ; F A S L-R 5^{\prime}$-ggacttgcctgttaaatgggc-3'; TNF- $\alpha-F \quad 5^{\prime}$-ccatgttgtagcaaaccctcaagctg-3'; TNF- $\alpha-R$ $5^{\prime}$-agactcggcaaagtcgagatagtcgg-3'; TNFR1-F $5^{\prime}$-agggga cagggagaagagag-3'; TNFR1-R $5^{\prime}$-gtgcacacggtgttctgttt-3'; TRAIL-F $\quad 5^{\prime}$-tagagaaggaagggcttcagtgaccg-3'; TRAIL- $R$ $5^{\prime}$-tcctctggtcccagttatgtgagctg-3' ${ }^{\prime}$; DR4-F $5^{\prime}$-actttggttgttcc gttgct-3'; DR4-R $5^{\prime}$-gaaacacaccctgtccatgc-3'; DR5-F $5^{\prime}$-tcacagttgcagccgtagtc-3'; DR5-R $5^{\prime}$-tcgctttcaggtaaggaa gg-3'; Caspase 8-F 5'-ggactacattccgcaaaggaagcaag-3'; Caspase $8-R 5^{\prime}$-tgggcacagactcttttcaggatgtc- $3^{\prime}$.
Following quantitative PCR, $5 \mu \mathrm{l}$ of each sample was loaded onto a $1.5 \%$ agarose gel, containing ethidium bromide, electrophoresed and visualized under UV light.

\section{Statistics}

Mean and standard deviation were calculated for the outcome variables. Because of the non-normal data distribution, the Kendall tau B test was used to calculate correlations. A two-tailed $P$-value equal to or less than 0.05 was considered significant. Because of the exploratory design of this study all tests were performed without $\alpha$ adjustment. Data analysis used SPSS for Windows 11.0.1 (SPSS, USA).

\section{Results}

\section{Histopathological Investigation}

Intervertebral disk tissue was scored based on an established method that characterizes the degenerative grade of the disk tissue. The method takes into account five parameters of pathological tissue transformation and results in a score ranging from 0 for undegenerated disk tissue up to 22 for heavily degenerated tissue. ${ }^{16}$ The total degenerative score of the 28 studied intervertebral disk specimen ranged from 2 to 12 with a mean score of 5.1, which indicates a mild disk degeneration. Tissue necrosis was not observed in any intervertebral disk. Changes in muccoid matrix composition ranged from 0 to 3 with a mean value of 1.6. Tear and cleft formation ranged from 0 to 2 with a mean value of 1.1 , which also suggests mild degeneration. Changes in tissue granularity ranged from 0 to 3 with a mean value of 0.5 , and cellularity and cluster formation was observed in a range from 0 to 4 with a mean value of 1.8, which indicates tissue degeneration at the beginning of a progressing state (Table 1).

\section{In Vivo Expression of TRAIL and Caspase 8 Correlates with Tissue Degeneration of Intervertebral Disk Tissue}

Because isolation of cells from intervertebral disk tissue is an in vitro manipulation that might also influence the protein expression pattern of the cells, we investigated the quantitative gene expression of Fas, FasL, TNF- $\alpha$, TNFR1, TRAIL, DR4 and caspase 8 in native intervertebral disk tissue of 24 donors on mRNA level. Gene expression analysis revealed FasL to be expressed in 13 of 24 cases, Fas (17 of 24), TNF- $\alpha$ (11 of 24), TNFR1 (16 of 24), TRAIL (23 of 24), DR4 (15 of 24) and caspase 8 in 13 of 24 cases. By statistical correlation of the gene expression data with the corresponding parameters of tissue degeneration, we found significant positive correlations between TRAIL expression and degenerative score $\left(r^{2}=0.484 ; P=0.002\right)$ (Figure 1a), cellularity $\left(r^{2}=0.323 ; P=0.04\right)$, changes in muccoid matrix 
$\left(r^{2}=0.422 ; P=0.009\right)$ and occurrence of tears and clefts $\left(r^{2}=0.386 ; P=0.019\right)$. Also elevation of caspase 8 expression correlated with the degenerative score $\left(r^{2}=0.338 ; P=0.027\right)$ (Figure 1b). Fas, FasL, TNF- $\alpha, T N F R 1$ and DR4 showed no significant correlation on gene expression level to the degenerative score or other parameters of pathological tissue transformation.

\section{In Vitro Expression of Death Receptors DR4 and DR5 Correlates with Histopathology of Intervertebral Disk Tissue}

To further analyze on a single-cell level whether native intervertebral disk cells express members of the TNF/NGF family, we investigated intervertebral disk cells from 14 randomly chosen donors for the expression of Fas, FasL, TRAIL, DR4 and DR5 on protein level by flow cytometry. We also studied whether these isolated cells stained double positive for the receptor/ligand pairs Fas/FasL, Fas/TRAIL, FasL/TRAIL, DR4/DR5 (Table 2). Flow cytometry revealed $4.6 \%$ of the cells to express the FasL protein, $40.4 \%$ Fas, $36.1 \%$ TRAIL, $10.8 \%$ DR4 and $36.8 \%$ DR5. A correlation study of the detected protein expression with the assessed histological parameters resulted in significant correlations of DR4 expression with the total degenerative score $\left(r^{2}=0.52 ; P=0.014\right)$ (Figure 2f). In addition, protein expression of the TRAIL receptor DR5 positively correlated with tissue granularity $\left(r^{2}=0.486 ; P=0.03\right)$ (Figure 2g). Furthermore, a positive correlation to the degeneration score was observed for the detectable amount of cells that stained double positive for both trail receptors DR4/ DR5 $\left(r^{2}=0.496 ; 0.019\right)$. All other analyzed proteins were uncorrelated to signs of pathological tissue transformation.

FasL and TRAIL are Expressed in Intervertebral Disks and Degree of Tissue Degeneration Correlates with PARP Cleavage

To confirm the expression of the apoptosis-inducing ligands FasL and TRAIL in intervertebral disk
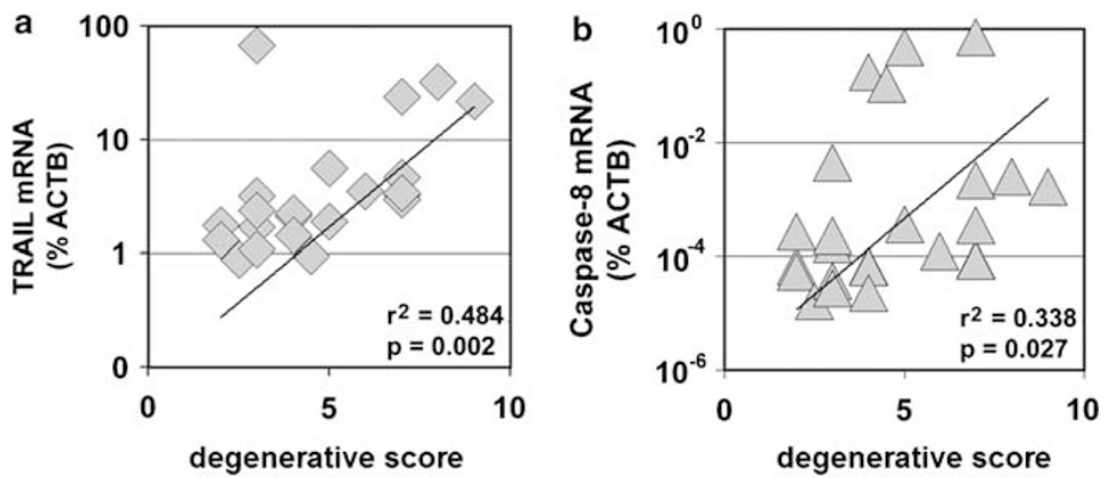

Figure 1 In vivo expression of TRAIL and caspase 8 correlates with tissue degeneration of intervertebral disk tissue. Relative gene expression levels in intervertebral disk tissue of 24 donors have been analyzed by LightCycler RealTime PCR. TRAIL (a) and caspase 8 (b) gene expression is shown as \% $\beta$-actin $(A C T B)$ plotted against the corresponding histological degeneration score of the donor. Correlation coefficients $\left(r^{2}\right)$ and $P$-values were calculated using the Kendall tau B test and SPSS software.

Table 2 Protein expression

\begin{tabular}{|c|c|c|c|c|c|c|c|c|c|c|c|}
\hline \multirow[t]{2}{*}{$I D$} & \multirow[t]{2}{*}{ Age } & \multirow[t]{2}{*}{$H D S$} & \multicolumn{9}{|c|}{ Flow cytometry ( $\%$ positive) } \\
\hline & & & Fas & FasL & TRAIL & DR4 & DR5 & Fas/FasL & Fas/TRAIL & FasL/TRAIL & DR4/DR5 \\
\hline 1 & 12 & 3 & 30.0 & 2.2 & 33.8 & 9.4 & 22.0 & 2.1 & 22.5 & 0.6 & 9.3 \\
\hline 20 & 49 & 3 & 22.3 & 1.7 & 13.5 & 5.9 & 32.2 & 1.4 & 10.1 & 0.4 & 6.0 \\
\hline 3 & 14 & 4 & 54.7 & 0.5 & 28.2 & 4.6 & 35.5 & 0.4 & 25.7 & 0.3 & 4.6 \\
\hline 22 & 50 & 5 & 27.0 & 1.5 & 15.6 & 2.7 & 27.7 & 1.4 & 11.9 & 0.4 & 2.6 \\
\hline 27 & 69 & 6 & 54.1 & 2.6 & 96.9 & 5.1 & 52.1 & 2.5 & 57.1 & 1.8 & 5.0 \\
\hline 4 & 14 & 7 & 14.7 & 1.9 & 25.3 & 6.0 & 36.6 & 1.2 & 12.3 & 0.1 & 5.9 \\
\hline 6 & 15 & 7 & 19.3 & 1.0 & 13.0 & 5.7 & 15.9 & 1.1 & 9.6 & 0.5 & 5.7 \\
\hline 10 & 16 & 7 & 9.6 & 0.9 & 31.2 & 6.1 & 32.2 & 0.9 & 6.9 & 0.8 & 6.0 \\
\hline 13 & 26 & 7 & 34.3 & 0.6 & 6.6 & 8.6 & 23.7 & 0.5 & 6.3 & 1.1 & 8.5 \\
\hline 25 & 55 & 7 & 55.9 & 27.1 & 51.2 & 12.6 & 33.0 & 27.0 & 57.7 & 21.0 & 12.6 \\
\hline 28 & 70 & 7 & 79.3 & 21.5 & 92.1 & 10.3 & 16.7 & 21.4 & 74.8 & 3.2 & 10.3 \\
\hline 23 & 54 & 8 & 42.5 & 2.0 & 6.6 & 6.1 & 48.7 & 1.9 & 6.1 & 0.7 & 6.1 \\
\hline 26 & 64 & 9 & 49.3 & 0.5 & 28.3 & 17.8 & 51.9 & 0.4 & 21.3 & 0.3 & 17.8 \\
\hline 7 & 15 & 10 & 72.0 & 0.8 & 62.9 & 51.1 & 86.7 & 15.5 & 56.4 & 2.1 & 51.2 \\
\hline Mean & 37.4 & 6.4 & 40.4 & 4.6 & 36.1 & 10.8 & 36.8 & 5.5 & 27.1 & 2.4 & 10.8 \\
\hline
\end{tabular}

HDS, histological degeneration score. 
FAS

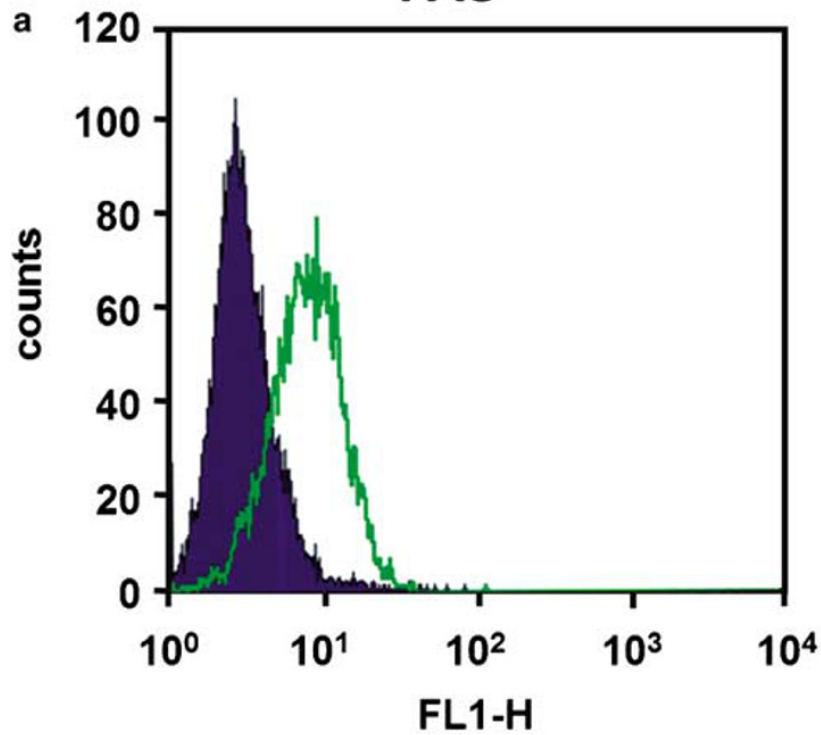

FASL

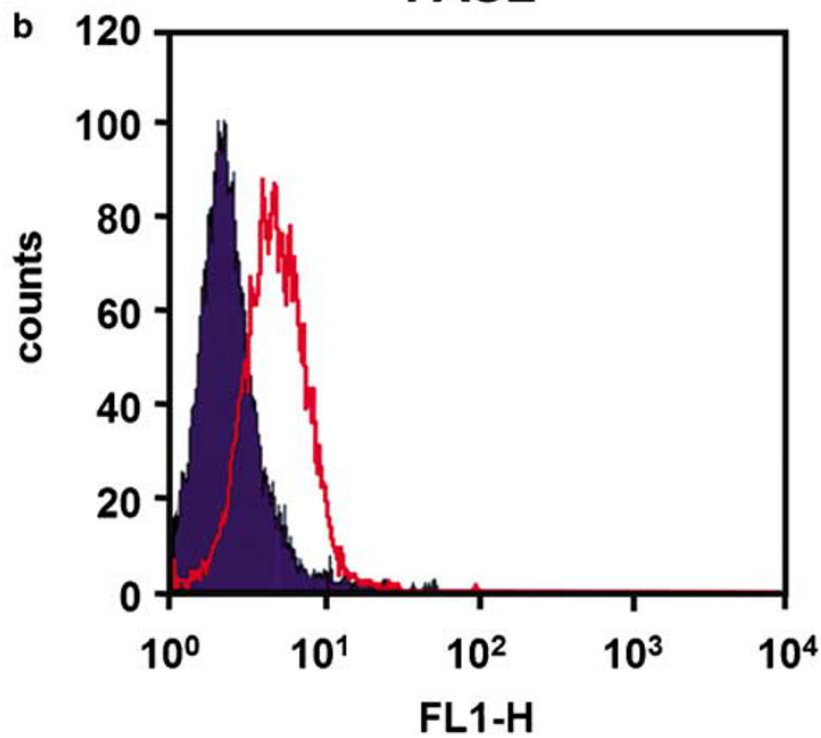

e

TRAIL

c

DR4
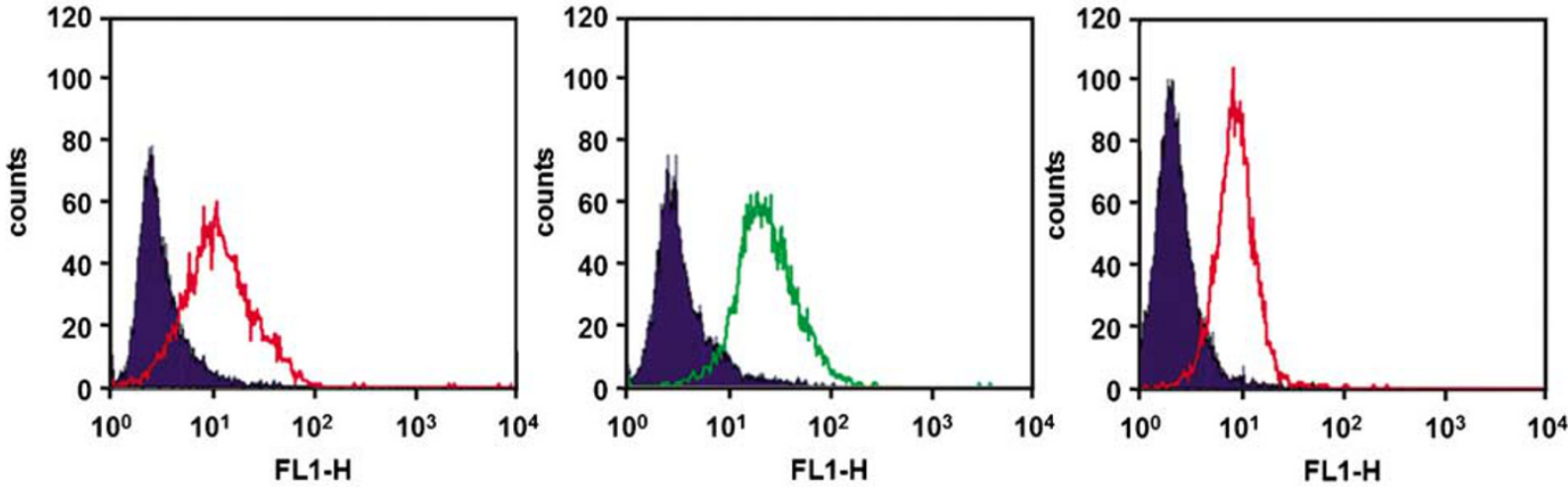

f
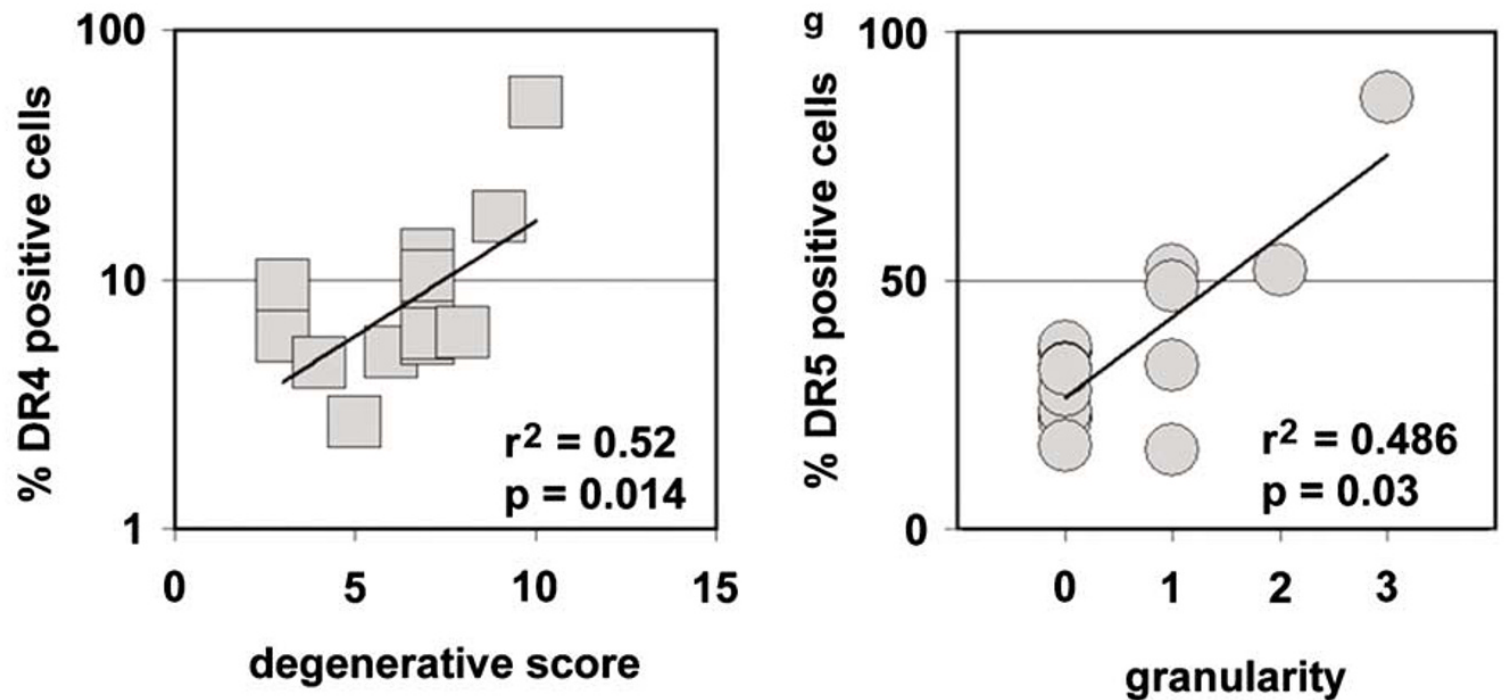

granularity

Figure 2 In vitro expression of death receptors DR4 and DR5 correlates with histopathology of intervertebral disk tissue. Isolated intervertebral disk cells from 14 randomly chosen donors were analyzed for the expression of Fas (a), FasL (b), DR4 (c) and DR5 (d) and TRAIL (e), on protein level by flow cytometry (Table 2). Percentage of DR4- (f) and DR5- (g) positive cells of 14 donors were plotted against the corresponding histological degeneration score or the degenerative parameter tissue granularity. Correlation coefficients $\left(r^{2}\right)$ and $P$-values were calculated using the Kendall tau B test and SPSS software. 
Table 3 PARP p85 cleavage

\begin{tabular}{rrrr}
\hline$I D$ & Age & HDS & PARP score \\
\hline 8 & 16 & 2 & 1.0 \\
17 & 31 & 2 & 2.3 \\
24 & 55 & 2 & 1.3 \\
19 & 45 & 3 & 2.7 \\
1 & 12 & 3 & 1.0 \\
9 & 16 & 3 & 0.3 \\
14 & 28 & 3 & 0.3 \\
15 & 28 & 3 & 0.7 \\
20 & 49 & 3 & 1.0 \\
3 & 14 & 4 & 1.3 \\
6 & 15 & 7 & 1.3 \\
10 & 16 & 7 & 1.7 \\
11 & 17 & 7 & 2.0 \\
13 & 26 & 7 & 2.3 \\
22 & 50 & 7 & 1.3 \\
25 & 55 & 7 & 2.0 \\
28 & 70 & 7 & 2.0 \\
23 & 54 & 8 & 2.7 \\
26 & 64 & 9 & 2.7 \\
7 & 15 & 10 & 3.0 \\
Mean & 33.8 & 5.2 & 1.7 \\
& & &
\end{tabular}

HDS, histological degeneration score.

PARP score: 0 , no cells; $1,1-5 \% ; 2,5-20 \% ; 3,>20 \%$.

tissue, we performed immunohistology and were able to detect both death ligands preferentially in the nucleus pulposus region of the studied disks (Figure 3a and c). To investigate whether PARP, the downstream target of both ligands, is activated, the caspase-mediated cleavage product PARP p85 was detected and the amount of apoptotic PARP p85positive cells per visual field was graded by three different investigators and the mean of the PARP grades was correlated to the grade of tissue degeneration (Table 3). In tissue with a degenerative score of 4 or below, nearly no PARP p85-positive cells were detectable (mean 1.2 PARP score= less than $5 \%$ positive cells), whereas in tissue with stronger signs of degeneration, the occurrence of PARP p85positive cells was significantly enhanced (mean 2.1 PARP score $=$ more than $20 \%$ positive cells; $P=0.0209$ ) indicating an increased rate of apoptosis (Figure 3f).

\section{Discussion}

This study evaluates the occurrence of ligand/ receptor pairs of the TNF/NGF family on intervertebral disk cells and studies whether the expression of these molecules correlates to the degenerative grade of the disk tissue defined by an established method which takes into account five parameters of pathological tissue transformation and results in a score ranging from 0 for undegenerated disk tissue up to 22 for heavily degenerated tissue. ${ }^{16}$
Intervertebral tissue degeneration and its associated changes within the extracellular matrix have been suggested as the pathophysiological reason for the development of various spinal deformities and consecutive loss of function. Most studies have demonstrated this process to be correlated to chronic and prolonged abnormal mechanical loading. ${ }^{17,39} E_{X}$ vivo studies were able to demonstrate a strong correlation of the load amplitude and impact duration with the degree of apoptosisinduced disk cell degeneration..$^{5,40,41}$ So far, several studies already demonstrated the crucial function of apoptotic mechanisms in the process of disk degeneration..$^{6,41-43}$ and the importance of apoptosis in diverse diseases associated with disk degeneration has been extensively reviewed. ${ }^{9}$

Induction of cell-surface-receptor-mediated apoptosis is primarily mediated by TNF- $\alpha$ /TNFR1, Fas/ FasL and TRAIL/DR4/DR5, respectively. High expression of TNF- $\alpha$ in traumatically injured intervertebral disks has already been reported..$^{42}$ Recently published data $^{44}$ suppose that apoptosis in traumatic intervertebral disk cells may be augmented by the extrinsic TNF- $\alpha$ - and TNFR1-mediated pathway by activating the initiator caspase 8 , and subsequently caspase $3 / 7$. In this context one study reported $^{45}$ that TNF- $\alpha$, even at low physiological concentrations, increases gene expression of matrix metalloproteinases and ADAM-TS (a disintegrin and metalloproteinase with thrombospondin motifs) known to deplete tissue proteoglycans in the early stages of intervertebral disk degeneration. Experimental findings from gene expression profiling ${ }^{46}$ and analyses of matrix degradation ${ }^{47}$ verified a decrease of molecules triggering anabolic processes, including BMP-2, BMP-7, IGF-1 or TIMP-1 in the extracellular matrix, and the involvement of TNF- $\alpha$ in the regulation of catabolic processes, which could be, at least, one possible explanation for the strongly limited reparative capabilities of the intervertebral disk in response to injury. In our study, we could detect $T N F-\alpha$ expression in $46 \%$ and TNFR1 expression in $67 \%$ of all analyzed samples. However, there was no correlation with the degenerative score of the tissue or one of the subscores of disk degradation, suggesting that $T N F-\alpha$ and/or TNFR1 are not directly involved in the degeneration process.

Studies from scoliotic and herniated disks suggest that the activation of the Fas/FasL system ${ }^{23}$ has the pivotal function in the progression of apoptosisassociated intervertebral disk degeneration. ${ }^{17,35}$

An examination of surgically obtained herniated lumbar disk tissues demonstrated the expression of FasL and its receptor Fas by immunohistochemistry. Although the percentage of Fas- and FasL-positive disk cells was significantly higher in noncontained compared to contained disks, no significant correlation with the degree of disk degeneration could be observed in these studies. However, the percentage of both Fas- and FasL-positive disk cells signifi- 

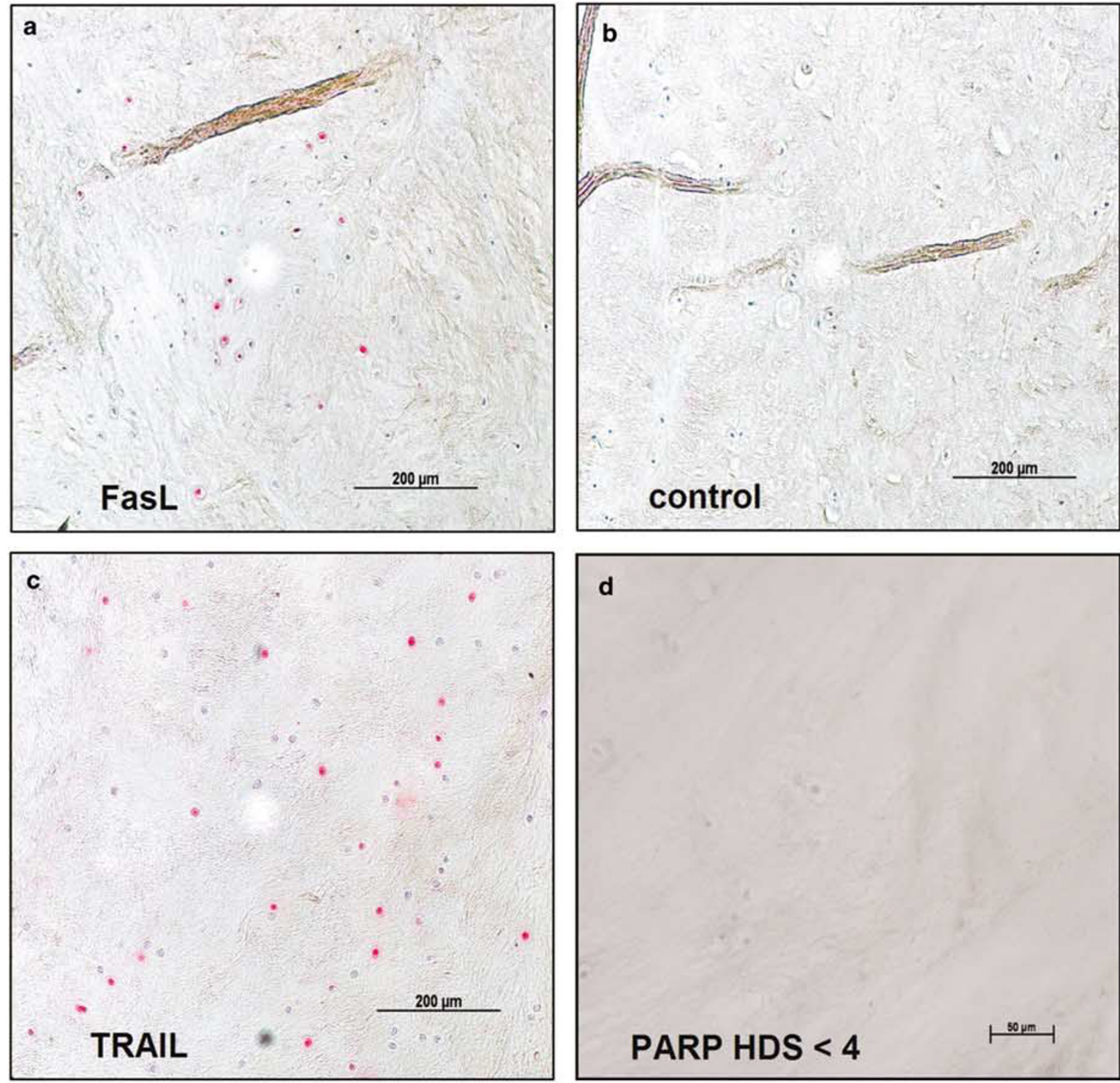

d

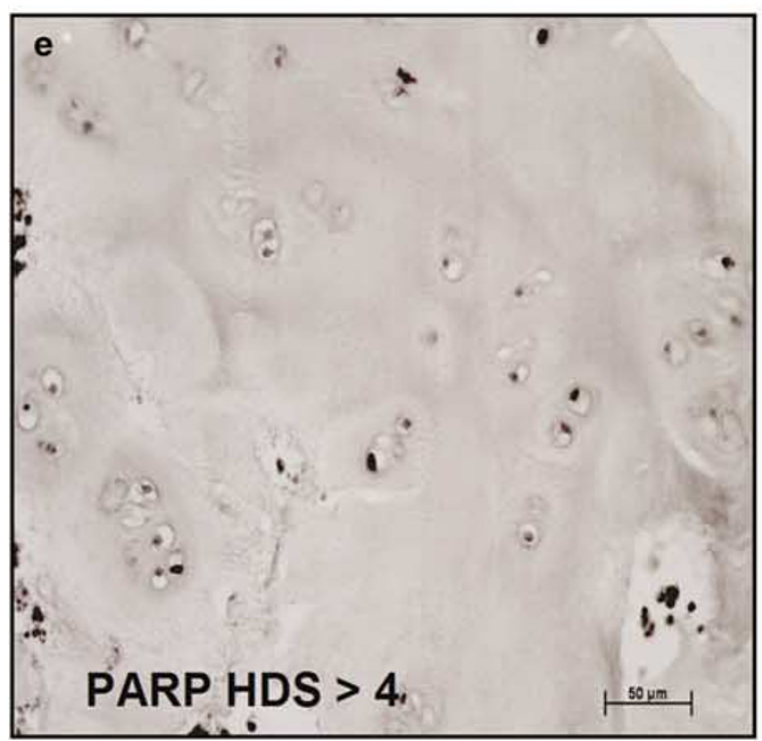

PARP HDS $<4$

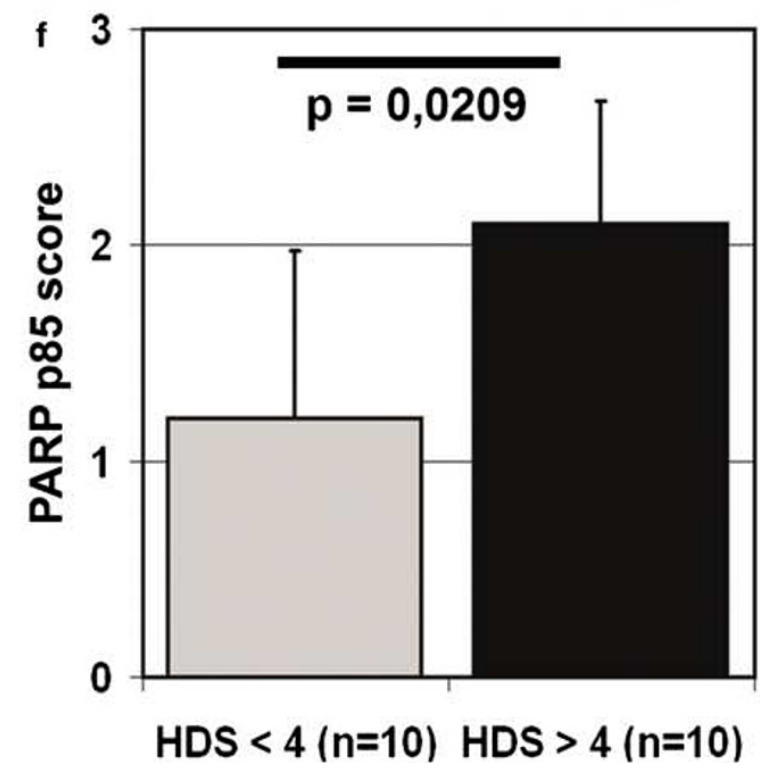


Figure 3 FasL and TRAIL are expressed in intervertebral disks and degree of tissue degeneration correlates with PARP cleavage. Representative result of immunohistochemistry carried out with specimen of 10 donors to detect both FasL (a) and TRAIL (c) death ligands in the nucleus pulposus region of the disk. (b) shows control immunohistochemistry without primary antibody. The cleaved substrate of caspase activity PARP p85 was detected as a marker of apoptosis in specimen of a subset of 20 donors (Table 3). Ten donors with a histological degeneration score (HDS) $<4$ and ten donors with an HDS $>4$ were analyzed and a representative donor is shown ( $\mathbf{d}$ and $\mathbf{e}$ ). The amount of PARP-positive staining cells per visual field was scored by three different investigators and differences between the groups were calculated using the Student's $t$-test (f). Mean \pm s.d. is shown. A $P$-value below 0.05 was considered significant.

cantly increased with the patient's age. ${ }^{6}$ Upregulation of Fas and FasL was further observed in a comparative analysis of trauma intervertebral disks vs degenerative intervertebral disks. ${ }^{44}$ In this study Fas mRNA expression was significantly increased in trauma and degenerative intervertebral disks compared to controls. Interestingly, FasL upregulation was only observed in degenerative intervertebral disks, whereas trauma intervertebral disks displayed an increase in $T N F-\alpha$ expression. In both kinds of intervertebral disks a marked increase of caspase 8, 9, 3 and 7 confirmed the induction of apoptosis in these tissues.

In our study, we could confirm FasL and Fas mRNA and protein expression in degenerated disks as well as a significant association of apoptosis with the degree of degeneration as shown by the caspasemediated cleavage of PARP. However, comparable to the TNF- $\alpha / T N F R 1$ system, no correlation with the degree of degeneration was observed for Fas/FasL expression, suggesting that Fas/FasL are not directly implicated in this process. As a possible function of the Fas/FasL system of intervertebral disk cells, the maintenance of an immunological privilege of the disk tissue has been suggested ${ }^{32}$ as it has already been described for the testis and the retina. ${ }^{32}$ Interestingly, a recent publication shows that FasL expression negatively correlates with ongoing progression of degeneration. ${ }^{48}$ In this concept, FasLexpressing disk cells would be enabled to induce apoptosis and kill infiltrating Fas expressing lymphocytes. ${ }^{49}$ In fact, clinical observations confirm an autoimmune reaction if the nucleus pulposus is exposed to the host immune system.

Although the involvement of apoptotic mechanisms in the process of disk degeneration is undoubted, the precise mediators are still unknown. In contrast to the TNF- $\alpha /$ TNF-R1 and the Fas/FasL system, little is known about the function of the TRAIL/DR4/DR5 system in intervertebral disks. TRAIL is a member of the TNF/NGF family that triggers apoptosis on engagement of one of its two agonistic receptors, named DR4 (death receptor 4$)^{50}$ and DR5 (death receptor 5). ${ }^{51}$ Although TRAIL has gained considerable interest in oncology for its specific antitumoral activity, until now there is only one study available that addressed the possible involvement of the TRAIL receptor DR4 in disk herniation. ${ }^{52}$ To the best of our knowledge, our study is the first attempt to study TRAIL and DR4/DR5 expression in correlation to ongoing pathological changes of intervertebral disk tissue on a broad age range. Our study provides evidence that TRAIL expression correlated with overall degenerative changes of the intervertebral disk tissue as well as with cellular parameters and degeneration associated tissue transformations. Furthermore, we were also able to correlate an increase of caspase 8 expression and increase of PARP cleavage, strongly suggesting the activation of apoptotic processes. In addition, we observed a correlation of the expression of both TRAIL receptors with the ongoing state of disk degeneration of the donor tissue on a cellular level. These findings suggest a direct involvement of the TRAIL/DR4/DR5 system in the apoptosis-associated progression of pathological degenerative tissue transformation of the intervertebral disk.

The collective data presented by others and our study hence support the theory that both proinflammatory mediators and the mechanically induced signaling events have an important impact on intervertebral disk cell matrix changes, including the potential to promote disk cell apoptosis and consecutive disk degeneration. ${ }^{43,53}$ Data recently published by Tschoeke et $a l^{44}$ suggest that the observed changes in intervertebral disk cells involve extrinsic signaling mechanisms as shown by $T N F-\alpha$ upregulation and increased caspase 8 activity.

Further analyses certainly are necessary to evaluate the importance of distinct intervertebral disk regions (annulus vs nucleus) within the apoptotic process in degenerative intervertebral disks in more detail. In addition, it would be desirable to study the importance of potential cross-links between the extrinsic and intrinsic apoptotic pathways. ${ }^{6,7,35}$ Recent attempts to supplement the disk's regenerative capabilities and prevent tissue degradation have already shown promising results using both cell-based and gene therapeutic approaches. ${ }^{54-56}$ Furthermore, an elegant therapy approach that would directly address and neutralize the apoptosis-inducing ligand TRAIL might help to at least delay progression of disk degeneration. A comparable approach that involves FasL function perturbing antibodies has already shown promising results in the regeneration and functional recovery after spinal cord injury in an animal model. $^{57}$

Taken together, to the best of our knowledge, this is the first study that shows that both in intervertebral disk tissue and in cultured intervertebral disk 
cells receptors of the apoptosis-inducing TNF/NGF family and their ligands are expressed and in case of TRAIL, DR4 and DR5 are correlated to the degenerative state of the tissue, suggesting a crucial function for the induction of apoptosis in disk tissue.

\section{Acknowledgements}

This study was funded by a grant of the Orthopaedic University Clinic Heidelberg. We especially thank A Eschelbeck, B Gmeiner, R Foehr and K Goetzke for excellent technical support. Furthermore, we are grateful to Mrs Dr Zimmermann-Stenzel for carrying out the statistical evaluation.

\section{Disclosure/conflict of interest}

The authors have no potential conflict of interest to declare.

\section{References}

1 Macfarlane GJ, Thomas E, Croft PR, et al. Predictors of early improvement in low back pain amongst consulters to general practice: the influence of pre-morbid and episode-related factors. Pain 1999;80:113-119.

2 Gruber HE, Hanley Jr EN. Analysis of aging and degeneration of the human intervertebral disc. Comparison of surgical specimens with normal controls. Spine 1998;23:751-757.

3 Gruber HE, Norton HJ, Hanley Jr EN. Anti-apoptotic effects of IGF-1 and PDGF on human intervertebral disc cells in vitro. Spine 2000;25:2153-2157.

4 Lotz JC, Colliou OK, Chin JR, et al. Compressioninduced degeneration of the intervertebral disc: an in vivo mouse model and finite-element study. Spine 1998;23:2493-2506.

5 Lotz JC, Chin JR. Intervertebral disc cell death is dependent on the magnitude and duration of spinal loading. Spine 2000;25:1477-1483.

6 Park JB, Chang H, Kim KW. Expression of Fas ligand and apoptosis of disc cells in herniated lumbar disc tissue. Spine 2001;26:618-621.

7 Park JB, Kim KW, Han CW, et al. Expression of Fas receptor on disc cells in herniated lumbar disc tissue. Spine 2001;26:142-146.

8 Wang YJ, Shi Q, Lu WW, et al. Cervical intervertebral disc degeneration induced by unbalanced dynamic and static forces: a novel in vivo rat model. Spine 2006; 31:1532-1538.

9 Anderson DG, Tannoury C. Molecular pathogenic factors in symptomatic disc degeneration. Spine J 2005;5: 260S-266S.

10 Buckwalter JA. Aging and degeneration of the human intervertebral disc. Spine 1995;20:1307-1314.

11 Freemont AJ, Watkins A, Le Maitre C, et al. Current understanding of cellular and molecular events in intervertebral disc degeneration: implications for therapy. J Pathol 2002;196:374-379.

12 Horner HA, Urban JP. 2001 Volvo award winner in basic science studies: effect of nutrient supply on the viability of cells from the nucleus pulposus of the intervertebral disc. Spine 2001;26:2543-2549.

13 Nerlich AG, Schleicher ED, Boos N. 1997 Volvo award winner in basic science studies. Immunohistologic markers for age-related changes of human lumbar intervertebral discs. Spine 1997;22:2781-2795.

14 Weiler C, Nerlich AG, Bachmeier BE, et al. Expression and distribution of tumor necrosis factor alpha in human lumbar intervertebral discs: a study in surgical specimen and autopsy controls. Spine 2005;30:44-53.

15 Bibby SR, Jones DA, Ripley RM, et al. Metabolism of the intervertebral disc: effects of low levels of oxygen, glucose, and $\mathrm{pH}$ on rates of energy metabolism of bovine nucleus pulposus cells. Spine 2005;30:487-496.

16 Boos N, Weissbach S, Rohrbach H, et al. Classification of age-related changes in lumbar intervertebral discs: 2002 Volvo award in basic science. Spine 2002;27: 2631-2644.

17 Chen B, Fellenberg J, Wang H, et al. Occurrence and regional distribution of apoptosis in scoliotic discs. Spine 2005;30:519-524.

18 Melrose J, Gurr KR, Cole TC, et al. The influence of scoliosis and ageing on proteoglycan heterogeneity in the human intervertebral disc. J Orthop Res 1991;9: 68-77.

19 Bechmann I, Mor G, Nilsen J, et al. FasL (CD95L, Apo1L) is expressed in the normal rat and human brain: evidence for the existence of an immunological brain barrier. Glia 1999;27:62-74.

20 Bellgrau D, Gold D, Selawry H, et al. A role for CD95 ligand in preventing graft rejection. Nature 1995;377: 630-632.

21 Griffith TS, Brunner T, Fletcher SM, et al. Fas ligandinduced apoptosis as a mechanism of immune privilege. Science 1995;270:1189-1192.

22 Greil R, Egle A, Villunger A. On the role and significance of Fas (Apo-1/CD95) ligand (FasL) expression in immune privileged tissues and cancer cells using multiple myeloma as a model. Leuk Lymphoma 1998;31:477-490.

23 Nagata S, Golstein P. The Fas death factor. Science 1995;267:1449-1456

24 Nagata S. Apoptosis by death factor. Cell 1997;88: $355-365$

25 Suda T, Takahashi T, Golstein P, et al. Molecular cloning and expression of the Fas ligand, a novel member of the tumor necrosis factor family. Cell 1993;75:1169-1178.

26 Suda T, Okazaki T, Naito Y, et al. Expression of the Fas ligand in cells of T cell lineage. J Immunol 1995;154: 3806-3813.

27 Asahara H, Hasumuna T, Kobata T, et al. Expression of Fas antigen and Fas ligand in the rheumatoid synovial tissue. Clin Immunol Immunopathol 1996;81:27-34.

28 Krammer PH. CD95(APO-1/Fas)-mediated apoptosis: live and let die. Adv Immunol 1999;71:163-210.

29 Mita E, Hayashi N. [Molecular biology of Fas antigenFas ligand system]. Nippon Rinsho 1996;54:1736-1740.

30 Nagata S. Fas-induced apoptosis. Intern Med 1998;37: 179-181.

31 Hashimoto S, Setareh M, Ochs RL, et al. Fas/Fas ligand expression and induction of apoptosis in chondrocytes. Arthritis Rheum 1997;40:1749-1755.

32 Takada T, Nishida K, Doita M, et al. Fas ligand exists on intervertebral disc cells: a potential molecular mechanism for immune privilege of the disc. Spine 2002;27:1526-1530. 
33 Lippke JA, Gu Y, Sarnecki C, et al. Identification and characterization of CPP32/Mch2 homolog 1, a novel cysteine protease similar to CPP32. J Biol Chem 1996; 271:1825-1828.

34 Schreiber V, de Murcia G, de Murcia JM. A eukaryotic expression vector for the study of nuclear localization signals. Gene 1994;150:411-412.

35 Park JB, Park IC, Park SJ, et al. Anti-apoptotic effects of caspase inhibitors on rat intervertebral disc cells. J Bone Joint Surg Am 2006;88:771-779.

36 Bhardwaj A, Aggarwal BB. Receptor-mediated choreography of life and death. J Clin Immunol 2003;23: 317-332.

$37 \mathrm{Kim} \mathrm{KW}$, Kim YS, Ha KY, et al. An autocrine or paracrine Fas-mediated counterattack: a potential mechanism for apoptosis of notochordal cells in intact rat nucleus pulposus. Spine 2005;30:1247-1251.

38 Kischkel FC, Lawrence DA, Chuntharapai A, et al. Apo2L/TRAIL-dependent recruitment of endogenous FADD and caspase-8 to death receptors 4 and 5 . Immunity 2000;12:611-620.

39 Kohyama K, Saura R, Doita M, et al. Intervertebral disc cell apoptosis by nitric oxide: biological understanding of intervertebral disc degeneration. Kobe J Med Sci 2000;46:283-295.

40 Ariga K, Miyamoto S, Nakase T, et al. The relationship between apoptosis of endplate chondrocytes and aging and degeneration of the intervertebral disc. Spine 2001;26:2414-2420.

41 Ariga K, Yonenobu K, Nakase T, et al. Mechanical stress-induced apoptosis of endplate chondrocytes in organ-cultured mouse intervertebral discs: an ex vivo study. Spine 2003;28:1528-1533.

42 Heyde CE, Tschoeke SK, Hellmuth M, et al. Trauma induces apoptosis in human thoracolumbar intervertebral discs. BMC Clin Pathol 2006;6:5.

43 Zhao CQ, Jiang LS, Dai LY. Programmed cell death in intervertebral disc degeneration. Apoptosis 2006;11: 2079-2088.

44 Tschoeke SK, Hellmuth M, Hostmann A, et al. Apoptosis of human intervertebral discs after trauma compares to degenerated discs involving both receptor-mediated and mitochondrial-dependent pathways. J Orthop Res 2008;26:999-1006.
45 Seguin CA, Pilliar RM, Roughley PJ, et al. Tumor necrosis factor-alpha modulates matrix production and catabolism in nucleus pulposus tissue. Spine 2005;30:1940-1948.

46 Sobajima S, Kompel JF, Kim JS, et al. A slowly progressive and reproducible animal model of intervertebral disc degeneration characterized by MRI, X-ray, and histology. Spine 2005;30:15-24.

47 Le Maitre CL, Pockert A, Buttle DJ, et al. Matrix synthesis and degradation in human intervertebral disc degeneration. Biochem Soc Trans 2007;35:652-655.

48 Kaneyama S, Nishida K, Takada T, et al. Fas ligand expression on human nucleus pulposus cells decreases with disc degeneration processes. J Orthop Sci 2008;13:130-135.

49 Takeuchi T, Ueki T, Nishimatsu H, et al. Accelerated rejection of Fas ligand-expressing heart grafts. J Immunol 1999;162:518-522.

50 Pan G, O’Rourke K, Chinnaiyan AM, et al. The receptor for the cytotoxic ligand TRAIL. Science 1997;276:111-113.

51 Chaudhary PM, Eby M, Jasmin A, et al. Death receptor 5 , a new member of the TNFR family, and DR4 induce FADD-dependent apoptosis and activate the NFkappaB pathway. Immunity 1997;7:821-830.

52 Zhang L, Niu T, Yang SY, et al. The occurrence and regional distribution of DR4 on herniated disc cells: a potential apoptosis pathway in lumbar intervertebral disc. Spine 2008;33:422-427.

53 Burke JG, Watson RW, McCormack D, et al. Intervertebral discs which cause low back pain secrete high levels of proinflammatory mediators. J Bone Joint Surg Br 2002;84:196-201.

54 Anderson DG, Albert TJ, Fraser JK, et al. Cellular therapy for disc degeneration. Spine 2005;30:S14-S19.

55 Le Visage C, Kim SW, Tateno K, et al. Interaction of human mesenchymal stem cells with disc cells: changes in extracellular matrix biosynthesis. Spine 2006;31:2036-2042.

56 Levicoff EA, Gilbertson LG, Kang JD. Gene therapy for disc repair. Spine J 2005;5:287S-296S.

57 Demjen D, Klussmann S, Kleber S, et al. Neutralization of CD95 ligand promotes regeneration and functional recovery after spinal cord injury. Nat Med 2004;10: 389-395. 